\title{
Is it possible to distinguish the understanding of denture adhesive between Japanese dental students and Indonesian peers by a questionnaire?
}

\author{
Shinsuke Sadamori, * Taizo Hamada,* Guang Hong,* Makoto Kawamura,** Nobuyuki Nakai,* and Arifzan Razak*** \\ * Department of Prosthetic Dentistry, Graduate School of Biomedical Sciences, Hiroshima University, Hiroshima, Japan \\ ** Preventive Dentistry, Hiroshima University Hospital \\ *** Department of Prosthodontics, Faculty of Dentistry, Airlangga University, Surabaya, Indonesia
}

\begin{abstract}
The purpose of this study was to compare cross-national differences in the recognition of denture adhesive between dental students. The design of the research was cross-cultural differences. The research was done in Japan and Indonesia. Seventy-seven dental students from Japan and Indonesia were surveyed using a questionnaire regarding knowledge/comprehension of denture adhesive (in Japanese and Indonesian versions respectively). Logistic regression using the Wald method showed that it was possible to distinguish Japanese dental students from Indonesian peers with a probability of 96.1 per cent by using 3 items out of 12 . For the question of "How many domestic products denture adhesive do you know?" 85 per cent of the Japanese dentists answered "less than 3", whereas 10 percent of Indonesian subjects did so. It was concluded that there were big differences between Japanese and Indonesian dental students' understanding and experience of denture adhesive.
\end{abstract}

Key words: denture adhesive, cross-national differences, dental students, questionnaire, Japan, Indonesia

Correspondence: Dr Shinsuke Sadamori, Department of Prosthetic Dentistry, Graduate School of Biomedical Sciences, Hiroshima University, 1-2-3 Kasumi, Minami-ku, Hiroshima, 734-8553, Japan, Tel: +81-82-257-5681, FAX: +81-82-257-5684, E-mail: tsada@hiroshima-u.ac.jp

\section{INTRODUCTION}

Nowadays, there seems to be many differences among countries in the use of denture adhesive. Grasso ${ }^{1}$ reported that $75 \%$ of dentists have recommended the use of denture adhesives. In general, denture wearers' attitude toward denture adhesives is likely to be favorable: better retention of their dentures; more comfortable when chewing and speaking with denture adhesives than without. 2,3 Meanwhile, opinions about denture adhesives have not been consent among dental professionals yet: 1) negative attitudes; prolongation of a wearing period of ill-fitting dentures $;{ }^{4}$ allergens and irritants to denture-bearing tissues; 5,6 2) positive attitudes; prevention of food particles impaction under the denture, reduction of unfavorable mechanical irritation, and improvement in denture stability and retention. ${ }^{7-11}$

A recently published study reported that there were many differences in understanding and experience of denture adhesive in the clinic between Japanese and Indonesian dentists. Japanese dentists had more information about denture adhesives. However, in the clinic, Indonesian dentists tended to apply denture adhesive (DA) to patients more often than Japanese dentists did. The Japanese dentists did not tend to apply denture adhesive to their patients in spite of having the opportunity to see TV commercials about such application.
According to Forss and Widström's survey, ${ }^{12}$ the patients' opinions had a strong influence on selection of restorative materials. The differences in the use of DA between the two countries might be due to a difference in need of the patient, and/or in understanding the disadvantage of DA. Ozcan et al. ${ }^{13}$ stated that denture adhesive should be taught more intensively at dental school. As dental students have not enough knowledge about dental services, TV commercials about DA may have an effect on awareness and interest of dental students. Hence, it is interesting to know whether or not the similar results would be obtained between Japanese and Indonesian dental students. The purpose of this study was to clarify dental students' recognition of denture adhesive between the two countries and to examine if there were differences in their understanding of denture adhesive (factors determined by their nationality).

\section{MATERIALS AND METHODS}

In this study, 77 subjects were asked to complete and return a structured questionnaire. The subjects in this pilot study were selected from undergraduate dental students in Japan (Hiroshima University, Hiroshima) and Indonesia (Airlangga University, Surabaya). They included 47 students of fourth-year at Hiroshima University and 29 
students of fifth-year at Airlangga University. Mean age of the Japanese students was not statistically significant compared to that of Indonesian peers (23.6 and 23.1 yrs respectively). In the survey, the distribution and collection of the questionnaire was instituted by the staff of this survey in 2002. This questionnaire was administered after an explanation was given to all subjects about the aim of this survey, and understanding and consent from all subjects was gained.

The questionnaire had been in Japanese and then was translated into English. Then, it was discussed among the staff at Airlangga University, and this survey was instituted using the same estimation criterion between the two countries (in Japanese and Indonesian version respectively). The answers were evaluated in three steps of "No" or "Nothing" (score 0), "Yes, but a little" or "Occasionally" (score 1) and "Yes, very much" or "Often" (score 2).

Logistic regression analysis was carried out on the dependent variable (country). The Wald statistic was used to test the null hypothesis that the regression coefficients were zero. The Nagelkerke $\mathrm{R}^{2}$ was used to discriminate how well the model is able to distinguish between the interest and knowledge of dental students in the two countries. All analyses were computed using SPSS for Windows operating system (SPSS 10, SPSS Japan Inc., Tokyo, Japan).

\section{RESULTS}

The recovery rate was 98.7 per cent: Hiroshima University 100 per cent, Airlangga University 96.7 per cent. Questionnaire items and percentage distribution of responses were shown in table 1. Compared with Indonesian students, more Japanese students not only knew DA but also had a clear understanding of its purpose and directions for its use (Q1 and 2). The proportion of students who knew imported DA products was higher in Indonesia, while the proportion of students who knew domesticallyproduced DA was higher in Japan (Q4 and 5). Students in both countries were similarly educated about DA in dental school or elsewhere (Q6 and 7). Japanese students also recognized DA in TV commercial messages more often than Indonesian students (Q8). The proportion of students who were familiar with alternative products of DA was slightly higher in Japan, while more Indonesian students were familiar with DA in the clinic (Q9, 10). There was a significant difference in the knowledge of the therapeutic effects of DA between students in both countries (Q11). As to the price of DA, more Indonesian students believed that it was reasonable than did Japanese students (Q12).

Table 2 shows the estimated coefficient and related statistics from the logistic regression model that predicts group membership. The model contained three variables.

Table 1. Questionnaire items and percentage distribution of the answers by country

\begin{tabular}{|c|c|c|c|c|c|c|c|}
\hline \multirow{2}{*}{\multicolumn{4}{|c|}{ Item descriptions }} & \multicolumn{4}{|c|}{ category score } \\
\hline & & & & \multirow{2}{*}{$\frac{2}{30}$} & \multirow{2}{*}{$\frac{1}{68}$} & \multirow{2}{*}{$\begin{array}{l}0 \\
2\end{array}$} & \multirow{2}{*}{$\frac{P}{* *}$} \\
\hline Q1. & Do you know the denture adhesive? & A & JPN & & & & \\
\hline & & & INA & 3 & 79 & 17 & \\
\hline \multirow[t]{2}{*}{ Q2. } & Do you know any purposes of the denture adhesive? & A & JPN & 43 & 57 & 0 & $* * *$ \\
\hline & & & INA & 7 & 72 & 21 & \\
\hline \multirow[t]{2}{*}{ Q3. } & Do you know any disadvantages of the denture adhesive? & A & JPN & 15 & 77 & 9 & NS \\
\hline & & & INA & 24 & 72 & 3 & \\
\hline \multirow[t]{2}{*}{ Q4. } & How many imported products of denture adhesive do & B & JPN & 0 & 13 & 87 & $* * *$ \\
\hline & you know? & & INA & 41 & 59 & 0 & \\
\hline \multirow[t]{2}{*}{ Q5. } & How many domestic products of denture adhesive do you & B & JPN & 15 & 74 & 11 & $* * *$ \\
\hline & know? & & INA & 90 & 10 & 0 & \\
\hline \multirow[t]{2}{*}{ Q6. } & Have you ever been taught about the denture adhesive? & $\mathrm{C}$ & JPN & 19 & 79 & 2 & NS \\
\hline & & & INA & 3 & 90 & 7 & \\
\hline \multirow[t]{2}{*}{ Q7. } & Have you ever seen the denture adhesive in books or & $\mathrm{C}$ & JPN & 26 & 66 & 9 & NS \\
\hline & lecture meetings? & & INA & 38 & 62 & 0 & \\
\hline \multirow[t]{2}{*}{ Q8. } & Have you ever seen any TV commercials about the & $\mathrm{C}$ & JPN & 62 & 34 & 4 & $* *$ \\
\hline & denture adhesive? & & INA & 79 & 3 & 17 & \\
\hline \multirow[t]{2}{*}{ Q9. } & Do you know any goods instead of the denture adhesive? & A & JPN & 4 & 28 & 68 & $* * *$ \\
\hline & & & INA & 90 & 10 & 0 & \\
\hline \multirow[t]{2}{*}{ Q10. } & Have you ever seen the denture adhesive in the clinic? & $\mathrm{C}$ & JPN & 4 & 17 & 79 & $* * *$ \\
\hline & & & INA & 17 & 72 & 10 & \\
\hline \multirow[t]{2}{*}{ Q11. } & Do you think the use of denture adhesive is more effective & A & JPN & 9 & 60 & 32 & $*$ \\
\hline & than medical intervention such as relining? & & INA & 24 & 66 & 10 & \\
\hline \multirow[t]{2}{*}{ Q12. } & Do you think the price of denture adhesives is reasonable? & A & JPN & 2 & 66 & 32 & $* * *$ \\
\hline & & & INA & 86 & 14 & 0 & \\
\hline
\end{tabular}

A 2: Yes, very much, 1: Yes, but a little, 0: No

в 2: Three and more, 1: Less than three, 0: Nothing

C 2: Yes, often, 1: Yes, occasionally, 0: No

* $: \mathrm{P}<0.05, * *: \mathrm{P}<0.01, * * *: \mathrm{P}<0.001$, NS: Not Significant 
Table 2. Results of binary logistic regression analysis using Wald method (forward stepwise)

\begin{tabular}{|c|c|c|c|c|c|c|}
\hline Item No. & $\mathrm{B}$ & S.E. & Wald chisquare & Freedom & $\mathrm{P}$ & $\operatorname{Exp}(\mathrm{B})$ \\
\hline \multicolumn{7}{|l|}{ Forward Stepwise (Wald) } \\
\hline Q2: Understanding of purposes of the use of DA* & -4.90 & 1.36 & 12.90 & 1 & 0.000 & 0.01 \\
\hline Q9: Knowledge about goods instead of DA* & 1.98 & 0.84 & 5.58 & 1 & 0.018 & 7.24 \\
\hline Q4: Number of imported DA* & 3.31 & 1.28 & 6.74 & 1 & 0.009 & 27.44 \\
\hline
\end{tabular}

* denture adhesive

Variables were entered in steps 1 to 3 Q2, Q9, Q4 in that order.

by forward stepwise method $(\mathrm{P}<0.01)$ : 22 (Understanding of purposes of the use of DA), Q9 (Knowledge of goods instead of DA), Q4 (Number of imported products of DA).

Table 3 showed that 45 Japanese students $(95.7 \%)$ and 28 Indonesian students $(96.6 \%)$ were correctly predicted by the model. The Nagelkerke $\mathrm{R}^{2}$ statistic was 0.907 ; that is, 90.7 per cent of the variation in the outcome variable was explained by the model.

Table 3. Observed and predicted group membership using Wald method

\begin{tabular}{lrcc}
\hline \multicolumn{4}{c}{ Predicted country } \\
\hline \multicolumn{1}{c}{ Country } & Japan & Indonesia & $\begin{array}{c}\text { Percentage } \\
\text { correct }\end{array}$ \\
\hline $\begin{array}{l}\text { Forward Stepwise (Wald) } \\
\text { Japan }\end{array}$ & 45 & 2 & 95.7 \\
$\begin{array}{l}\text { Indonesia } \\
\text { Total }\end{array}$ & 1 & 28 & 96.6 \\
\hline
\end{tabular}

The cut value is 0.50

Nagelkerke R2 $=0.907$

\section{DISCUSSION}

Using only 3 items regarding DA out of 12 , nationality of the dental students in Japan and Indonesia was almost correctly predicted (96.1 per cent) by the model. It was inferred that not only education of DA in dental school but also information of DA in TV commercial messages was more prevalent in Japan. It is assumed to be important to teach particularly the advantages and disadvantages of denture adhesive in professional education. It is a problem that students learn DA from TV instead of lectures in dental school.

A lower proportion of Japanese students thought that the price of DA was reasonable, while almost all of the Indonesian peers appeared to feel it reasonable. In our previous study, there was no difference in the answers between dentists in both countries. Since students in either country equally seemed to have no clinical experiences of application of DA and to have not realized its effects, this difference could be ascribed to the differences in information obtained mainly from mass media such as TV.
Also, the difference in the economic power between the countries would have affected their answers. In addition, the answers to the questions regarding imported and domestic DA products may have reflected the difference in power of DA production between the two countries.

The results obtained in response to Q5 and Q8 could be due to the fact that mass media is more developed in Japan than in Indonesia. Mass media about DA in Indonesia is unfortunately less developed than in Japan, but, to take the converse point of view, it is anticipated that less harm would be exerted from mass media influence.

In a study of diffusion of innovation it was reported that information flowed more directly from mass media while influences indirectly via personal communication (by health/care personnel et al.). ${ }^{14}$ The diffusion rate varies depending on the degree of "relative advantage", such as economic profitability, alleviation of discomfort, retrenchment of time and labor, and immediacy of benefit. In actual clinics, patients often complain of instability of dentures, insufficient maintenance power, and so on. If we take these circumstances into consideration, an explosive diffusion of DA in the general public, without the expert's remarks, would be anticipated.

In Japan, mass media is more developed in comparison with Indonesia, and it offers the appropriate information service from the specialist in mass media. We are in an age when medical care goods (such as denture adhesive) are diffused via TV and the internet. In days ahead it is necessary to send out accurate information via TV and the internet. Students should be learned DA based on evidence more properly in dental school, and the information of DA might be provided for the people from specialists.

Using only 3 items out of 12 (Q2: understanding of purposes of the use of denture adhesive, Q9: knowledge of goods other than denture adhesive, and Q4: number of imported products of denture adhesive) out of 12 , nationality of the dental students in Japan and Indonesia was almost correctly predicted (96.1 per cent) by the model. acknowledgements

\section{ACKNOWLEDGEMENTS}

This study was supported in part by Grant-in-Aid for Scientific Research (Grant No.16390617) from Japan Society for the Promotion of Science. 


\section{REFERENCES}

1. Grasso JE. Denture adhesives: Changing attitudes. J Am Dent Assoc 1996; 127:90-6.

2. Kelsey CC, Lang BR, Wang R- F. Examining patients' responses about the effectiveness of five denture adhesive pastes. J am Dent Assoc 1997; 128:1532-8.

3. Benson D, Rothman RS, Sims TN. The effect of a denture adhesive on the oral mucosa and vertical dimension of complete denture patients. J South Calif Dent Assoc 1972; 40:468-73.

4. Instruments and Equipment (US) Council on Dental Materials. Dentist's desk reference. Chicago: American Dental Association; 1981. p. 422-33.

5. Heatwell CM, Rahn AO. Syllabus of complete dentures. $3^{\text {rd }}$ ed. Philadelphia: Lea \& Febiger, 1980; p. 98.

6. Hogan W. Allergic reaction to adhesive denture powders. NY State Dent J 1954; 20:65-6.

7. Adisman KI. The use of denture adhesive as an aid to denture treatment. J Prosthet Dent 1989; 62:711-5.
8. Boone M. Analysis of soluble and insoluble denture adhesive and their relationship to tissue irritation and bone resorption. Compend Cont Educ Dent 1984; 4(Supplement):22-5.

9. Karlsson S, Swartz B. Effect of denture adhesive on mandibular denture dislodgment. Quintessence Int 1990; 21:625-7.

10. Grasso JE, Rendell J, Gay T. Effect of denture adhesive on the retention and stability of maxillary dentures. J Prosthet Dent 1994; 72:399-405.

11. Sadamori S, Hamada T, Hong G, Nakai N, Kawamura M, Razak A. Comparison of the recognition of denture adhesive between Japanese and Indonesia dentists: A pilot study. Maj. Ked. Gigi (Dent J) 2005; 38(4):189-93.

12. Fors $\mathrm{N}$, Widstrom E. Factors influencing the selection of restorative materials in dental care in Finland. Journal of Dentistry 1996; 24:257-62.

13. Ozcan M, Kulak Y, Arikan A, Silahtar E. The attitude of complete denture wearers towards denture adhesive in Istanbul. J Oral Rehabil 2004; 31:131-4.

14. Rogers EM. Diffusion of innovations. $3^{\text {rd }}$ ed. New York: The Free Press; 1983. 